\title{
Perception of Program Administrators and Student Representatives on the Implementation of Return Service Agreement in Selected Institutions in the Philippines
}

\author{
Jonathan P. Guevarra, ${ }^{1}$ Paolo Victor N. Medina, ${ }^{2}$ Michelle D. Avelino, ${ }^{3}$ Ma. Rhenea Anne M. Cengca, ${ }^{3}$ \\ Mikko Anthony L. Ting, ${ }^{3}$ Azar G. Agbon, ${ }^{3}$ Danika Joy D. Bardelosa, ${ }^{3}$ Demi Arantxa C. Sepe, ${ }^{3}$ \\ Aubrey B. Lara ${ }^{3}$ and Carl Abelardo T. Antonio ${ }^{4}$ \\ ${ }^{1}$ Department of Health Promotion and Education, College of Public Health, University of the Philippines Manila \\ ${ }^{2}$ Department of Family and Community Medicine, College of Medicine and Philippine General Hospital, University of the Philippines Manila \\ ${ }^{3}$ College of Public Health, University of the Philippines Manila \\ ${ }^{4}$ Department of Health Policy and Administration, College of Public Health, University of the Philippines Manila
}

\begin{abstract}
Objectives. The study aimed to determine the perception of program administrators and students on the implementation of return service agreement (RSA) in the Philippines. It examined the different components of, and opportunities, and challenges in the implementation of RSA of selected institutions.

Methods. Key informant interviews using a topic guide were conducted with ten program administrators and student representatives from selected institutions implementing a return service policy. Interviews were transcribed and responses in Filipino were translated to English. Open coding and focused coding were performed to identify categories and themes from the interview transcripts.
\end{abstract}

Results. Addressing human resource for health $(\mathrm{HRH})$ needs of the country is a common rationale behind RSA implementation among the institutions sampled for the study. A notable difference in implementation arrangements is the manner of rendering service. Majority of RSA programs require promisors to be employed in any part of the Philippines in need of health workers, while other RSA programs recruit students from rural areas in order to deploy them later on in their hometowns. There is also an apparent lack of institutionalized mechanisms for job placement for students to fulfill their return service obligations. One challenge in most institutions is the need for a formal monitoring and evaluation scheme for the policy.

Conclusion. Integration of the voice of stakeholders is critical in the conceptualization, development, and implementation of RSA policies. This will ensure that issues attendant to operationalization are mitigated if not outrightly avoided.

Key Words: compulsory service, mandatory service, return service agreement, health human resource, program administrators, student representatives, Philippines

\section{INTRODUCTION}

Corresponding author: Jonathan P. Guevarra, RN, RM, MAN

Department of Health Promotion and Education

College of Public Health

University of the Philippines Manila

Lara Hall, 625 Pedro Gil Street, Ermita 1000 Manila, Philippines

Email: jpguevarra2@up.edu.ph
The success of delivering health care services depends on the availability and capabilities of the human resource component of a health care delivery system. ${ }^{1}$ Thus, human resources are generally recognized as the most vital part of any health system. Health outcomes are greatly affected by the access to health personnel and health service. Geographic maldistribution of health workers is a persistent problem present in both developed and developing countries. 
Several factors contribute to this geographical disparity such as an individual's social background, better work conditions, and higher compensation in urban areas and developed countries. Urban areas have generally higher densities of health workers owing to the presence of teaching hospitals and populations with higher incomes. ${ }^{2}$

While the Philippines produces a sufficient number of health professionals annually, maldistribution still exists in the health care delivery system. One phenomenon that has contributed to this is the increasing out-migration of health professionals, especially of nurses, doctors, and physical and occupational therapists. There is also a high unemployment rate for HRH who remain in the country because health professionals still prefer to work in urban areas although there are job vacancies in rural areas. ${ }^{3,4}$

Various programs and policies have been initiated to address the problem on HRH. One way is through the implementation of a mandatory service, or sometimes referred to as return service agreement (RSA). Return service policies in the Philippines date back to the 1950s when the Philippine Medical Association implemented a mandatory rural service for physicians as a special project. ${ }^{5}$ Through the years, other government agencies and academic institutions established similar RSA policies. ${ }^{6}$

Currently, there is limited information regarding the implementation of RSA in the country. Hence, this study was done to determine the perception of program administrators and student representatives on the implementation of RSA in the Philippines. Specifically, it aimed to: a) describe the components of the current implementation of RSA in the Philippines; b) identify legal, financial, developmental, labor market, incentive, and other implications of RSA when implemented; and c) identify opportunities and challenges in the implementation of the RSA. Results of this study can contribute to the pool of knowledge in the areas of public health administration and human resource development. Moreover, findings can be used as an input in the formulation of both local and national RSA policymaking efforts.

\section{METHODS}

\section{Study Design}

A qualitative study design was utilized to determine the perceptions of program managers and student representatives of selected institutions who are currently involved in the implementation of a return service policy in the Philippines.

\section{Study Population}

Key informant interviews were conducted with selected individuals from institutions that are currently involved in the implementation of an RSA. The key informants were purposively selected on the premise that they: a) were knowledgeable of the implementation of return service policy within their institution; b) possessed the mandate to represent the institution or student body in an official manner; and c) were willing to give consent for the interview. Representatives from institutions not implementing, or have not implemented, the said policy were not included as potential source of information.

Individuals who met the criteria were invited to participate in the research as key informants. Letters were sent to the potential key informants. Confirmation on their availability for the interview was secured through phone calls and/or SMS and direct messaging on social media platforms. Informed consent was obtained at a time convenient for the interviewee. No follow-up interviews were conducted.

\section{Key informant interview}

The KII was conducted with the aid of an interview guide. The interview guide consisted of four sections. The first section included questions on the background of the key informants. The second part comprised of questions on the procedures in implementing the return service policy in their institution, including its scope and rationale. The third section of the guide focused on the support systems for its implementation. For the heads of agencies, this part tackled the legal, financial, labor market, and career development considerations in the implementation of the policy, while for the student leaders, it focused on their peers' expectation on their future career roles. Lastly, the data collection tool asked for feedback on the implementation of RSA.

\section{Processing of interview output}

Individual interviews by project investigators and trained research assistants working in pairs, were conducted during the period of October 2016 to January 2017. The transcriptions and analyses were done from October 2016 to February 2017. Audio recordings of the interviews were transcribed verbatim and responses in Filipino were translated to English. Open coding of interview transcripts was done independently by two researchers and any discrepancy between the two were settled through a consensus. Focused coding was done by two project investigators and discrepancies between the two were settled through a consensus. After performing the focused coding, categories and themes relevant to the implementation of return service policy were identified.

\section{Technical review and ethics clearance}

This study was reviewed by a technical panel convened by the Philippine Council for Health Research and Development (PCHRD) (No. 001050) and received ethical clearance from the University of the Philippines Manila Research Ethics Board (No. 2016-360-01). This study was part of a larger project of the research group on Feasibility of a Return of Service Agreement for Selected Human Resources for Health in the Philippines. 


\section{RESULTS}

\section{Profile of Key Informants}

A total of six program administrators and six student representatives from institutions with RSA in the Philippines were identified as potential key informants in this study. However, only 10 individuals agreed to be interviewed. Of this number, six were student representatives while the other four were heads of agencies or programs. The key informants who participated in the study were the (a) heads of Philippine academic institutions implementing a return service policy for health professions students; (b) student representatives from academic institutions implementing a return service policy for health professions students, and (c) heads of other Philippine government agencies implementing return service agreements.

The key informants were involved in the implementation of RSA in their respective institutions for varying lengths of time. Some have been involved long-term while others have only participated for a short period of time. Some served as the program organizer and developer. This is especially true for the heads of agencies who are either appointed as head or member of the committees involved in the formation, implementation, and evaluation of the policy. For some, they entered their respective institutions with the policy being implemented already thus, they took part in formulating amendments to it. Student representatives who participated in this study shared that they also served as link between the student body and the implementing body of RSA in their school. These informants were also involved in the information dissemination and monitoring of the RSA policy implementation.

Three main themes were identified from the key informant interviews: (1) return service policy of the institution, (2) support systems for return service policy implementation, and (3) feedback on return service policy implementation (Table 1). The succeeding section provides detailed description of each theme.

Table 1. Three main themes identified from key informant interviews

Theme

Categories

Return Service Policy of the Institution

Rationale for RSA Implementation Contractual Arrangements Selection and Recruitment Implementation Policies and Processes

Support Systems for Return Service Policy Implementation

\begin{tabular}{lc} 
& $\begin{array}{c}\text { Career Development and Labor } \\
\text { Market Considerations }\end{array}$ \\
\hline $\begin{array}{l}\text { Feedback on Return Service } \\
\text { Policy Implementation }\end{array}$ & $\begin{array}{c}\text { RSA Implementation Gains } \\
\text { and Successes } \\
\text { RSA Implementation Challenges }\end{array}$ \\
\hline
\end{tabular}

\section{Return Service Policy of the Institution}

\section{Rationale for RSA Implementation}

According to one informant, "the essence of the [return] service is to address brain drain but more so than that, the policy aims to reach the far flung areas which are not reached by medical services." Representatives from most of the other participating institutions echoed this when asked about the rationale of the policy. RSA was implemented as a means to address imbalance in the distribution of human resources for health. Similar to the problem in other countries, the Philippines has been facing problems on health workers migrating abroad or from rural to urban areas in the country. The RSA programs of the participating institutions aimed to meet the demand of access to health services and health workers in the Philippines by requiring subjects of the program to work within the country, and sometimes, to be deployed to far-flung areas of the country. On the other hand, one of the participating institutions implemented RSA in exchange for the scholarships given to their employees in order to equip them with necessary competencies that would ultimately contribute to national development.

\section{Contractual Arrangements}

From the institutions that participated in this study, entry to RSA can either be an absolute admission requirement or an obligation that is incorporated into their scholarship program. In some institutions, students are required to enter into an agreement before being admitted. The RSA may also be part of a scholarship program where service is rendered in return for a fully or partially subsidized tuition fee. One particular participating institution employed categorization of scholarship that indicates a student's qualification for its scholarship and return service program.

\section{Selection and Recruitment}

As mentioned earlier, some institutions have RSA as an absolute admission requirement. The students who enter into this contract follow the normal admission process of the institution; that is to pass the entrance examination and submit the needed requirements, one of which is the signed RSA contract.

For the recruitment of promisors in a certain institution, students are from rural areas, preferably geographically isolated and disadvantaged areas (GIDA) or communities with low health professional to population ratio. These students are first endorsed by their community following a set of admission guidelines given by the institution.

\section{Implementation Policies and Processes}

Obligation fulfilment. In most cases of RSA, the promisor is required to sign a return service obligation contract before being able to enter the degree program. The contract provisions of some participating institutions take effect when the promisor has enrolled 60 units of classes 
while some other institution's contracts become effective as soon as the promisor enters the program, hence, promisors have to maintain satisfactory grades. The duration of service obligation differs from one institution to another - some require two years, some require 1,000 hours while others require twice the number of years that the promisor spent on studying. Rendering of service also varies across institutions, and may be done during the student's academic years, after graduation, or after passing the licensure examination. Most of the promisors can render service in any field that is related to his/her profession as long as he/she remains in the Philippines. Some institutions require graduates to render service in his/her sending community or institution.

Compliance. To ensure compliance, some institutions withhold the credentials of the promisors to prevent them from seeking employment overseas, taking further studies in other schools, or transferring to another job. In some forms of RSA, if the promisor fails to fulfill the terms, he/ she is required to pay the equivalent amount, sometimes with additional fees, that was granted to him/her during the whole period of his/her schooling. In other institutions, the only accepted form of payment is through the obligatory service. In special cases, such as inability to pay the equivalent amount or being incapacitated, supplemental contracts are stipulated by the institution and the promisor.

Monitoring procedure. As part of the monitoring, graduates are usually required to report annually to the institution and submit proof of employment. One institution requires the promisors to report four times during the duration of their service. Some of the institutions who took part in the study organized a committee for the purpose of monitoring the RSA implementation. Others do not have a clear monitoring scheme thus, aside from the annual report, promisors are informally tracked through contacts within the same social and professional networks and regular social gatherings. Administrative staff or faculty working with the promisor can serve as point person for monitoring.

\section{Support Systems for Return Service Policy Implementation}

\section{Preparatory Activities}

In terms of support systems, institutions also prepare their promisors or students for future practice in the context of RSA in their respective fields. This is done by incorporating into the curriculum a community field work and/or lectures that emphasize public health. In one institution, students are oriented by developing a socially-relevant curriculum that is geared towards community and public health. One informant commented that "when the students are exposed to the actual scenarios in the community, their drive to serve the country is strengthened" and that "this is a very important factor for one's education." Preparatory activities for professional placement are also conducted such as career fairs, internships, and fora on their career options.

\section{Future role expectations}

On expected future career roles, student representatives from the academic institutions implementing RSA mainly talked about overseas employment and local professional practice. Some promisors, particularly those from the field of nursing, physical therapy, and occupational therapy, are expected by their family and peers to work abroad for better compensation and/or to join their families. On the other hand, some are expected to take further studies but still practice their profession here in the Philippines.

\section{Legal and Financial Considerations}

In formulating and implementing the return service policy and program, institutions have to address the legal, financial, labor market, and career development considerations of the policy or program. These are the different aspects of the support systems and implementation capabilities of the institution with an RSA program. Legal considerations include the legal capacities and tools in enforcing the policy. Institutions use contracts for a legally-binding RSA, while some have offices for other legal concerns such as noncompliance with the contract and academic deficiencies that affect fulfilment of service obligation. Implementation of RSA also has financial implications. There are institutions that do not have budgetary considerations and allocations while one of the participating institutions ties up with an external agency for funding of the scholarship and bursaries of the program subjects.

\section{Career Development and Labor Market Considerations}

Institutions also have to consider career development for the RSA subjects. Institutionalization of exposure to future career options prepares the promisors in choosing the right career track even before entering the workforce. There are formal partnerships with external institutions to provide continuing professional education. This is to further capacitate health workers while in service. One informant commented that aligning the curriculum to the available careers for the subjects of RSA is also important.

As for the labor market considerations, rendering service in itself supplies health workers in the Philippines. Institutions can also enter into partnerships with other agencies or institutions to secure job placement for graduates. One of the participating institutions enters into an agreement or contract with local government units that would obligate them to hire the graduates of the RSA program.

\section{Feedback on Return Service Policy Implementation}

\section{RSA Implementation Gains and Successes}

Generally, no formal evaluation of the policy has been done but nevertheless, key informants were able to enumerate their feedback on the implementation of RSA. Institutions have conveyed their positive reception to the idea and intention of the said policy. They mentioned the high 
compliance and retention rate of human resource for health in beneficiary areas and the support (i.e. financial) from external organizations as proofs of positive feedback.

\section{RSA Implementation Challenges}

All the informants expressed that RSA has good intentions. One informant said that "there is really no problem with return service as a concept" but commented that there are still program components to be improved. Difficulty in tracking the promisors is the most cited challenge among the participating institutions due to the absence of a formal monitoring and evaluation mechanism. Securing slots for a higher position in their organization was also included in the challenges met by an institution that offers scholarship to their employees. This is a challenge for those who want to progress further in their career. Student representatives stated that during the formulation of the policy, there is a need for student representation since, as promisors in the policy, they are the most affected stakeholder. Moreover, some see the policy as a restriction on their growth, especially on their career path. In addition, some institutions do not have a separate orientation devoted solely for the purpose of discussing all the pertinent provisions of RSA.

Lastly, some stakeholders also expressed their view that RSA is not a sustainable solution to address the HRH needs of the country. One informant commented that "if they really want to solve the brain drain and the poor overall health of the Filipinos, RSA is not the only solution. They should give ample money and supplies to the specialists in order for them to do their job which is to improve the overall health of the Philippines. "Basic educational system was also cited as an example of what needs to be improved as, according to another informant, this "handles the formative years" and "if the sense of nationalism or the will to serve in your country was inculcated in you, it's enough. There will be no need for the return service."

\section{DISCUSSION}

While the implementation of RSA in the Philippines demonstrates that institutions have the capacity to support the program and policy, the key informants perceive that there are still challenges that need to be addressed in order to successfully meet the primary objectives particular to individual institutions in implementing the RSA. As far as enforcement of the stipulations of any RSA program is concerned, institutions have been deemed able to manage the legal implications of entering into an agreement with the students and, in some cases, with external agencies. Among the participating institutions, budgetary considerations in the implementation of RSA were mostly not a concern.

\section{Differences in implementation of RSA}

There are differences in the manner of implementation of RSA among different institutions. These differences range from the most nuanced stipulation to more significant aspects of an RSA program. One of the most notable differences is in the manner of rendering service. Majority of the RSA programs require promisors to be employed in any part of the Philippines while other RSA programs recruit students from the rural areas in order to deploy them later on to their hometowns or other areas in need of health workers. The latter is similar to compulsory services and deployment programs being practiced in other countries as a means to address the disparities in the supply of $\mathrm{HRH}$ between rural and urban areas. ${ }^{2}$ Also, this recruitment of subjects from rural areas is strongly associated with rural practice. ${ }^{78}$ A student or RSA subject recruited from rural areas is more likely to choose to work in a rural setting.

Aside from the problem of the supply of human resources for health in terms of quantity, the quality of the health workers being deployed could also be a problem. In Mexico, while there has been a program that requires graduates to serve in rural areas and underserved communities, the human resources provided by the program are defined by underperformance and absenteeism. This is mostly due to lack of mentoring and enough preparation to be able to practice without supervision. ${ }^{9}$ This sort of shortcoming undermines the capability of return service programs to provide equitable health care and address the gaps in human resource distribution in the health sector. As for the institutions that participated, there were not any concerns regarding this problem. Participating institutions already have incorporated in their curricula subjects that would equip students for community service and public health. It has already been the intention of these institutions to equip students and members for community-oriented careers even before RSA programs were in place.

\section{System support for career development}

Except for a few, most of the institutions do not have program components that equip the subjects for future career development. For those that have, the system supports for career development that were noted include exposure to future career options, and partnership with external institutions to provide continuing professional education. One way to expand career development plans in the RSA program is to include components that give advantage to those who have completed the program. For example, in Indonesia, those who have completed mandatory service are more likely to be accepted in training hospitals for specialization. ${ }^{10}$ This puts the subjects of a mandatory service program at an advantage over those who have not gone through the program.

In terms of the mechanisms for securing appropriate employment and job placement for the promisors, there is an apparent lack of structured opportunities for students to fulfill their return service obligations. This could be considered one of the common weaknesses of the programs. Majority of the institutions do not have a clear placement 
process in place. After graduating, institutions do not facilitate the employment of the promisors or the students. On the other hand, one participating institution enters into a memorandum of agreement (MOA) with agencies that will hire promisors once the period of rendering service commences. However, even then, job placement may still be difficult due to the inconsistent availability of positions for the promisors. In the implementations of similar programs in other countries, different agencies are involved in the funding, training, and even in the deployment of the subjects of RSA. Mexico is one of the countries that have a national mandatory service policy in place where an NGO is involved in the implementation. There are mentorships in place along with rural facilities and clinics where subjects of the mandatory service are deployed. ${ }^{11}$ Thailand has also imposed a national mandatory service for rural areas. All the government-subsidized training institutions are included in the scope of the mandatory service. New health professionals are deployed to rural areas as means of paying back the government support for medical training. ${ }^{9}$

\section{Perceived challenges and shortcomings}

Lastly, the key informants cited common challenges in implementation of RSA - formal feedback and monitoring scheme. These two are apparent across the participating institutions. There is a lack of formal avenue for stakeholders especially promisors or students to provide feedback and evaluation of the program. This is critical should the institution plan to reform or improve the currently placed RSA policy and program. An assessment on the compulsory medical service in Ecuador from the physician's perspective was conducted. The paper cited the importance of feedback and perception of the health professionals subject to the mandatory service. Through obtaining feedback and insights from the deployed health professionals, the paper was able to shed light on the current situation of the mandatory service from the perspective of the physicians who were and are part of the program. ${ }^{12,13}$ The results obtained could be used in improving the current mandatory service program.

Another challenge in the implementation of RSA is the monitoring of those rendering service and those who have finished the program. Career progression of those who have finished the RSA program is of particular concern since it reflects the capacity of an institution to provide proper preparation for future practices. For institution aiming to address the lack of $\mathrm{HRH}$ in rural areas or GIDAs, the ability to monitor those who have finished the program can help in determining the retention rate in beneficiary areas like GIDAs and far-flung areas with low HRH to population ratio.

\section{CONCLUSION AND RECOMMENDATIONS}

This study sought to determine the perception of program administrators and student representatives from institutions currently implementing RSA. It also described the components of the policy namely; the legal, financial, career development, and labor market considerations of the implementing institutions, and the corresponding gaps in program implementation. Different institutions may have different ways of implementing RSA but appear to have the same rationale for doing so; that is to address the needs of HRH in the country and to contribute to national development. Stakeholders view the implementation of the policy as having good intentions but there are still areas that need to be improved. There was a strong perception that there is a need for establishing more formal and structured monitoring schemes for institutions implementing RSA. There is also a need for institutions to further strengthen their support on career development plans and equipping promisors for future practice. There is also an apparent lack of institutionalized mechanisms for job placement in order for students to fulfill their return service obligations.

Integration of the voice of stakeholders is critical in the conceptualization, development, and implementation of RSA policies. This will ensure that issues attendant to operationalization are mitigated if not outrightly avoided.

For future studies, it is recommended to include quantitative assessments of implementations and outcomes of programs in order to provide a more comprehensive perspective on the current implementation of policies and programs. It would also be helpful if researchers can include compliance rate of institutions on the implementation of RSA programs in their future research endeavors.

\section{Acknowledgments}

We acknowledge the critical inputs provided by the Health Human Resource Development Bureau and Health Policy Development and Planning Bureau, Department of Health, Republic of the Philippines in the technical report from which this paper was derived. Likewise, we significantly benefited from the critique received from anonymous external referees appointed by the Philippine Council for Health Research and Development, Department of Science and Technology, Republic of the Philippines.

\section{Statement of Authorship}

CTA conceptualized the project; JPG and PNM contributed to and approved the study design. JPG, MMC, MLT and CTA wrote the draft publishable manuscript, and prepared the responses to reviewers' comments. All authors participated in data collection and analysis, and approved the final version submitted.

\section{Author Disclosure}

At the time of the conduct of the study, authors MMC and $A B L$ are currently fulfilling their service obligation as a requirement in a return service agreement program. All authors declared no conflicts of interest. 


\section{Funding Source}

This research project has been funded through the Department of Health - Health Systems Research Management in collaboration with the Philippine Council for Health Research and Development. This article reflects the points of view and thoughts of the authors, and the information, conclusions, and recommendations presented are not to be misconstrued as those of the Department of Health nor of the Philippine Council for Health Research and Development. The material presented here however is done in the spirit of promoting open access and meaningful dialogue for policy/plan/program improvement, and the responsibility for its interpretation and use lies with the reader.

\section{REFERENCES}

1. World Health Organization. The World Health Report 2000: Health Systems: Improving Performance [Internet]. Geneva: World Health Organization. 2000 [cited 2017 Feb]. Available from: http://www. who.int/whr/2000/en/whr00_ch4_en.pdf?ua=1

2. Dussault G, Franceschini MC. Not enough there, too many here: understanding geographical imbalances in the distribution of the health workforce. Hum Resour Health. 2006; 4:12.

3. Department of Health, 2011-2016 National objectives for health, health sector reform agenda monographs [Internet]. Manila: Department of Public Health; 2011 [cited 2017 Feb]. Available from: http://www.doh.gov.ph/sites/default/files/publications/noh2016.pdf

4. World Health Organization, The Philippines health system review [Internet]. 2011 [cited $2017 \mathrm{Feb}$ ]. Available from: http://www.wpro. who.int/philippines/areas/health_systems/financing/philippines_ health_system_review.pdf.
5. Philippine Medical Association, PMA legacy [Internet]. nd [cited 2017 Feb]. Available from: https://www.philippinemedical association.org/pma-history.php.

6. Medina PN, Bardelosa DD, Lara AB, Avelino MD, Agbon AG, Cengca RM, et al. A historical perspective of mandatory service policy in the Philippines: A document analysis. Phil J Health Res Dev. 2018; 22(3):1-12.

7. Easterbrook M, Godwin M, Wilson R, Hodgetts G, Brown $\mathrm{G}$, Pong R, et al. Rural background and clinical rural rotations during medical training: effect on practice location. CMAJ. 1999; 160(8):1159-63.

8. Rabinowitz HK. Recruitment, retention, and follow-up of graduates of a program to increase the number of family physicians in rural and underserved areas. N Engl J Med. 1993; 328(13):934-9.

9. Van Wieren A, Palazuelos L, Elliott P, Arrieta J, Flores H, Palazuelos D. Service, training, mentorship: first report of an innovative education-support program to revitalize primary care social service in Chiapas, Mexico. Glob Health Action. 2014; 7:25139.

10. World Bank. Indonesia's Health Work Force: Issues and Options [Internet]. Singapore: Institute of Southeast Asian Studies. Washington, DC: World Bank. 1997 [cited 2017 Feb]. Available from: http://documents.worldbank.org/curated/en/713721468756329897/ pdf/multiOpage.pdf

11. Wilson NW, Couper ID, De Vries E, Reid S, Fish T, Marais BJ. A critical review of interventions to redress the inequitable distribution of healthcare professionals to rural and remote areas. Rural Remote Health. 2009 Apr-Jun; 9(2):1060.

12. Cavender A, Albán M. Compulsory medical service in Ecuador: the physician's perspective. Soc Sci Med. 1998; 47(12):1937-46.

13. Wiwanitkit V. Mandatory rural service for health care workers in Thailand. Rural Remote Health. 2011; 11(1):1583. 